\title{
The plant-based immunomodulator curcumin as a potential candidate for the development of an adjunctive therapy for cerebral malaria
}

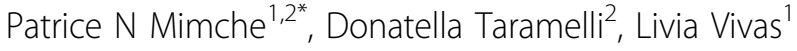

\begin{abstract}
The clinical manifestations of cerebral malaria (CM) are well correlated with underlying major pathophysiological events occurring during an acute malaria infection, the most important of which, is the adherence of parasitized erythrocytes to endothelial cells ultimately leading to sequestration and obstruction of brain capillaries. The consequent reduction in blood flow, leads to cerebral hypoxia, localized inflammation and release of neurotoxic molecules and inflammatory cytokines by the endothelium. The pharmacological regulation of these immunopathological processes by immunomodulatory molecules may potentially benefit the management of this severe complication. Adjunctive therapy of CM patients with an appropriate immunomodulatory compound possessing even moderate anti-malarial activity with the capacity to down regulate excess production of proinflammatory cytokines and expression of adhesion molecules, could potentially reverse cytoadherence, improve survival and prevent neurological sequelae. Current major drug discovery programmes are mainly focused on novel parasite targets and mechanisms of action. However, the discovery of compounds targeting the host remains a largely unexplored but attractive area of drug discovery research for the treatment of CM. This review discusses the properties of the plant immune-modifier curcumin and its potential as an adjunctive therapy for the management of this complication.
\end{abstract}

\section{Background}

Malaria, a disease caused by the Apicomplexan parasite of the genus Plasmodium, remains a serious public health threat in tropical and sub-tropical countries. It is the most important parasitic disease in humans with 300 to 500 million infected individuals every year. A proportion of these patients, mostly children under five, is at risk of developing severe anaemia or cerebral malaria (CM), which claims at least 1 million lives annually [1]. CM is a life-threatening complication of this infection which often occurs in non-immune individuals and those in which standard anti-malarial treatment has failed [2]. The effectiveness of anti-malarial treatment has been hampered by the emergence over the years of parasites resistant to almost all available anti-malarial drugs, including more lately the artemisinin class of drugs [3]. The reduced

\footnotetext{
* Correspondence: patmimche@hotmail.com

'Faculty of Infectious and Tropical Diseases, Department of Immunology and Infection, London School of Hygiene and Tropical Medicine, Keppel St, London WC1E 7HT, UK

Full list of author information is available at the end of the article
}

susceptibility to artemisinin derivatives recently identified in parasite isolates from SE Asia may compromise their efficacy for the treatment of $\mathrm{CM}$, which currently relies on artesunate or quinine [4], and is a worrying sign, as resistance may spread quickly to other parts of the world. Treatment failure of uncomplicated cases will inevitably increase the number of patients susceptible to develop severe complications. Therefore, there is an urgent need to develop new anti-malarial drugs and drug combinations or alternative strategies that circumvent the development of parasite drug resistance with the final aim of reducing the burden of this disease. These approaches may involve the identification of immune-modifying compounds with the capacity of enhancing macrophage's phagocytic activity, resulting in a reduction of the parasite biomass [5], downregulating excessive pro-inflammatory type 1 response, and reducing the expression of adhesion molecules and subsequent sequestration of parasitized erythrocytes (PE) (a hallmark of human $\mathrm{CM}$ ) in the cerebral microvasculature, thus improving survival of CM patients. Targeting the host, using immunomodulatory compounds, might be a 
useful strategy to complement the direct anti-parasitic activity of standard anti-malarial drugs and, as such, present a valuable tool in the management of $\mathrm{CM}$ and limit the emergence of resistant parasites. This review highlights the potential benefits that the plant-based natural product curcumin may have as an immunomodulator and as an adjunctive therapy for CM.

\section{Rationale for the use of immunomodulators for the treatment of cerebral malaria}

Cerebral malaria, one of the most severe complications of Plasmodium falciparum infections, is associated with various pathophysiological processes [6]. CM is mostly characterized by hyper-parasitaemia and by an excessive production of type 1 pro-inflammatory cytokines followed by up-regulation of endothelial cell adhesion molecule expression which contributes to the sequestration of PE in the brain microvasculature [7]. Understanding the molecular events implicated in the onset of $\mathrm{CM}$ would pave the way for the development of adjunctive therapies that may reduce cerebral damage by modulation of the pathological processes involved in its development, and thus prevent subsequent mortality and neurological sequalae. The association of immunomodulators with anti-malarial drugs could prove to be beneficial for the management of this condition [8]. This approach has already been tested using a variety of compounds in animal models of experimental cerebral malaria (ECM) [9-13] as well as in humans [14,15]. One of the strategies currently being investigated is to target the peroxisome proliferator activated receptor gamma (PPAR $\gamma$ ), a nuclear receptor involved in the regulation of the scavenger receptor CD36, which mediates nonopsonic phagocytosis of PE [16]. Pharmacological upregulation of CD36 in monocytes/macrophages by PPAR $\gamma$ agonists increases CD36 dependant phagocytosis of PE in vitro [17]. In a murine model of malaria, administration of the PPAR $\gamma$ agonist rosiglitazone, to Plasmodium chabaudi-infected mice, significantly decreased parasitaemia levels in wild type compared to CD36 knock-out mice and improved survival in Plasmodium bergheiANKA infected groups [12]. These findings warranted a randomized, double-blind, placebo-controlled trial to assess the efficacy of rosiglitazone, as an adjunctive therapy for the treatment of $P$. falciparum malaria. That trial showed a reduction in parasite clearance time and inflammatory markers in patients with uncomplicated malaria under a treatment regimen consisting of atovaquone + rosiglitazone compared to patients treated with atovaquone + placebo [18]. This evidence, together with a recent genome-wide association study linking a locus containing PPAR $\gamma$ with improved survival in a rodent malaria model [19], led us to speculate that pharmacologically targeting the signalling pathways involved in PPAR $\gamma / \mathrm{CD} 36$ expression during a malarial infection might improve CM treatment outcome.

Erythropoietin (Epo), a hormone produced by the kidneys which modulates the survival of developing erythroid precursors and production of new erythrocytes in the bone marrow, has been explored for the management of CM in animals and humans [9]. In the P. berghei-ANKA murine model of ECM, injection of high doses of Epo at the beginning of symptoms, significantly reduced the expression of pro-inflammatory cytokines (TNF and Interferon- $\gamma$ ) and improved the survival of mice with ECM compared to untreated mice [20]. Furthermore, in the same murine model of ECM, the doses of Epo were decreased six fold and its administration combined with artesunate was delayed to the sixth day post-infection. The results indicated that the survival rate was higher in mice receiving the combination Epo-artesunate than in mice treated with artesunate alone [21]. Clinical evidence for a neuroprotective role of Epo in humans emerged from a study of African children with CM in which high plasma levels of Epo were associated with a $70 \%$ reduction of the risk of being discharged with neurological sequelae [22]. These findings provided preliminary evidence for a clinical trial assessing the safety of Epo as an adjunctive therapy for children with CM in Mali. In this trial, the administration of high doses of Epo in CM children did not result in any side effects when evaluated on a shortterm basis, and no significant increase in the case fatality rate of the combined Epo-quinine administration was observed [15].

Activated charcoal is also being explored as a potential adjunctive therapy for the treatment of $\mathrm{CM}$. Oral activated charcoal (oAC) is highly effective at adsorbing a range of endotoxin-induced cytokines from the bloodstream including TNF, IL-1 and IL6 [23,24]. It was recently found that oAC protected mice against ECM and more importantly did not interfere with the pharmacokinetics of parenteral artesunate in humans [10]. The fact that oAC is a safe and well-tolerated compound already used in the clinic may accelerate its development as an adjunctive therapy for CM. Alternatively, the Rho-Kinase inhibitor, Fasudil, a drug approved for human use for cardio- and neuro-vascular diseases, is being proposed as an adjunctive therapy for severe malaria. Fasudil, which has anti-apoptogenic properties, protects and restores in vitro, the damage to the endothelial barrier resulting from $\mathrm{PE}$ adhesion $[25,26]$. It is worth mentioning that the adhesion of PE to human endothelial cells activates Rho Kinases and caspases leading to apoptosis [27]. Furthermore, Fasudil also modulates CM in $P$. berghei-ANKA infected mice 
[13]. PE-induced oxidative stress on endothelial cells is also involved in the pathology of CM and supplementation with anti-oxidant compounds protected endothelial cells in vitro[28]. In addition, treatment of P. bergheiinfected mice with the antioxidant $\mathrm{N}$-acetylcysteine (NAC) or the iron chelator, deferoxamine, in combination with chloroquine at the first signs of $\mathrm{CM}$, prevented the development of persistent cognitive dysfunction in infected mice [11]. However, a clinical trial of NAC in combination with artesunate as adjunct therapy failed to detect any benefit on outcome in patients with severe $P$. falciparum malaria [14]. Although all these treatment options for adjunctive therapies in $\mathrm{CM}$ seem promising (for a detailed review of adjunctive therapies for malaria see $[8,29-30])$, none of these compounds possess specific anti-malarial activity on their own. Therefore, plant-based immunomodulators displaying dual anti-malarial and immunodulatory mechanisms of action could become ideal candidates for anti-malarial drug development. This strategy has been explored with the natural product curcumin which shows immunomodulatory properties and has been found to prevent death from CM in P. berghei infected mice [13].

\section{Curcumin, a plant-based immunomodulator}

For thousands of years, some of the most effective antimalarial drugs have been derived from plants. Quinine and artemisinin, the only two molecules of choice for the treatment of severe malaria were isolated from the bark of the cinchona tree and the Chinese plant Artemisia annua, respectively. Although artemisinin and its derivatives have had a major impact on treatment when given in combination with other anti-malarials, they are limited by their short half-life, cost and safety concerns in pregnant women [31]. Poor distribution and access to these drugs among the population living in malaria endemic areas, means that many still rely on numerous herbal preparations or diets from traditional healers for the management of fever and malaria [32].

The natural product curcumin (1,7-bis(4-hydroxy 3-methoxy phenyl)-1,6-heptadiene-3,5-dione) is a polyphenolic compound extracted from the rhizome of Curcuma longa L. (family Zingiberaceae) (Figure 1) commonly used in the Asian sub-continent, especially in India, as a dietary spice to provide colour and flavour [33]. In traditional Indian medicine (Ayurveda), curcumin has been considered an effective drug for the

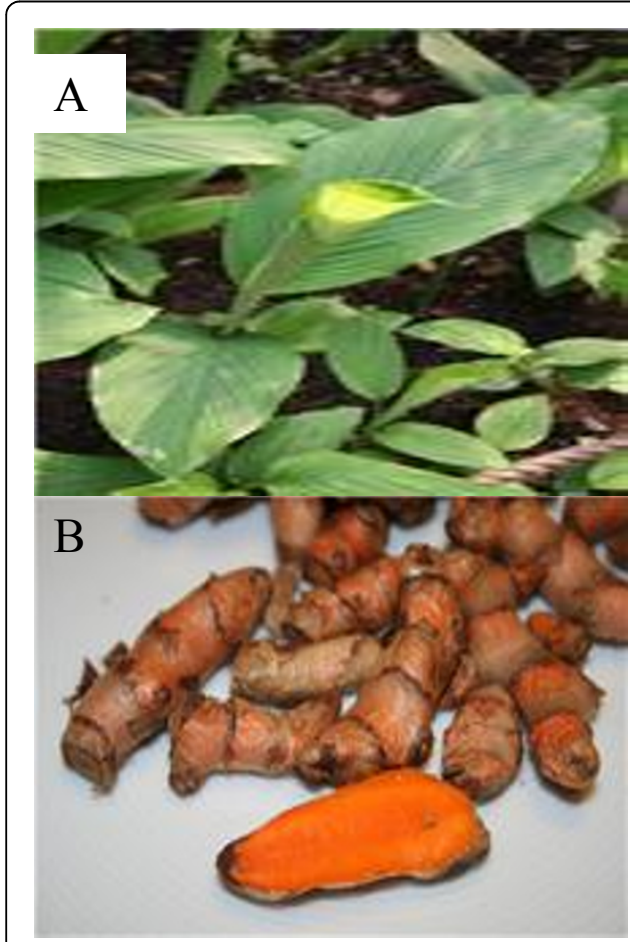

Curcuma longa
C<smiles>COc1cc(/C=C/C(=O)CC(=O)/C=C/c2ccc(O)c(OC)c2)ccc1O</smiles>

$\mathrm{D}$
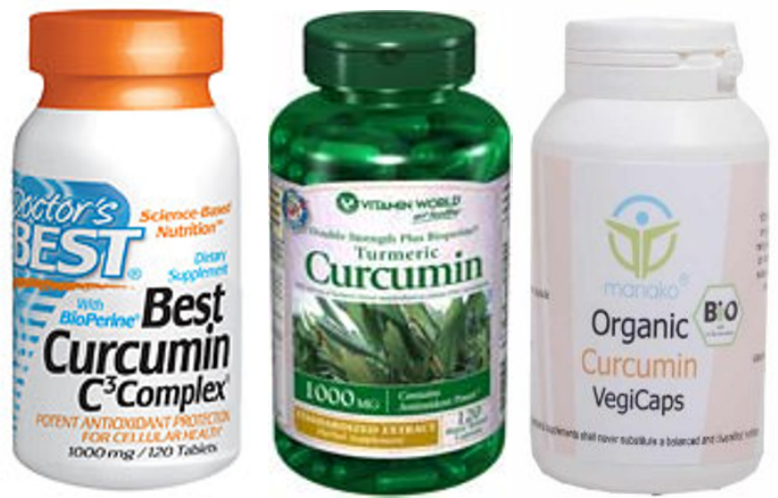

Curcumin-based products

Photo C Merlin Willcox

Figure 1 Chemical structure of curcumin. Curcumin (diferuloylmethane) is the active principle of the perennial herb Curcuma longa also known as turmeric (A) and is extracted from its roots (B). Molecular structure of curcumin (C). Curcumin-based products are available as dietary supplements (D). Curcuma longa photos @ Merlin Willcox. 
treatment of various disorders, and recent studies have substantiated and provided scientific evidence regarding its prophylactic and therapeutic potential, unravelling the anti-inflammatory, anti-carcinogenic, and anti-infectious activities of this natural product (Reviewed in [33-35]).

\section{Curcumin for malaria therapy?}

Studies carried out both in vitro and in vivo indicated that curcumin possesses a moderate anti-malarial activity with an $\mathrm{IC}_{50}$ ranging from $5-10 \mu \mathrm{M}$ in vitro $[36,37]$, [38]. In order to expand its potential as anti-malarial, curcumin derivatives have been synthesized and some of them demonstrated an increased anti-malarial activity in vitro with an $\mathrm{IC}_{50}$ of $\sim 400 \mathrm{nM}$ [39]. It was then demonstrated that this compound inhibits histone acetyltransferase (HAT) and increases the production of reactive oxygen species (ROS) in the malaria parasite [36]. Despite its moderate anti-malarial activity, other investigators suggested that the mechanism of action of curcumin might mirror that of artemisinin. In fact, artemisinin derivatives seem to target the parasite mitochondria and the flavin co-factors thus increasing the production of ROS. This reactivity is dependent on the endoperoxide bridge, which is essential for the antimalarial activity of artemisinins [40,41]. Curcumin seems to be more effective in killing the malaria parasite at the trophozoite stage while artemisinins display broad activity against all stages of the intraerythrocytic development of the malaria parasite [38]. Molecular docking experiments showed that curcumin can efficiently bind the malaria sarco-endoplasmic reticulum calcium ATPase (SERCA-PfATPase6) $[42,43]$ an ATP coupled $\mathrm{Ca}^{2+}$ ion pump involved in metabolic arrest which was first thought to be the biological target of artemisinin [44-46]. Interestingly, oral administration of curcumin followed by a single injection of the artemisinin derivative $\alpha-\beta$-arteether to $P$. berghei-infected mice, prevented recrudescence usually associated with $\alpha-\beta$ arteether monotherapy and ensured almost $100 \%$ survival of animals [47]. By contrast, a subsequent study showed that although curcumin had modest anti-malarial efficacy (delay in the peak parasitaemia) in mice, it was not able to modify the course of infection, when administered with artemisinin nor to reverse a $P$. chabaudi artemisinin-resistant phenotype [48]. The modest anti-malarial activity of curcumin in this model system was attributed to its immunomodulatory activities, which could be beneficial in delaying parasite growth. However, inherent differences between the two experimental murine models may help explain these contradicting results, since in contrast to $P$ berghei -ANKA, $P$ chabaudi causes a non lethal infection and does not lead to CM in CD1 mice [48].

\section{Curcumin as an adjunctive therapy for severe/cerebral malaria infection \\ Curcumin as a modulator of the innate immune response to malaria infection}

The severity of malaria infections is often associated with a large parasite biomass which triggers defence mechanisms that hinder parasite multiplication and are, therefore, important contributing factors in host survival [49]. A key feature of curcumin is that it possesses both anti-oxidant and pro-oxidant activities [50,51]. Available evidence supporting a protective role of ROS in malaria has emerged from animal and human studies. In humans, the elevated production of oxygen radicals was associated with faster parasite clearance in children with uncomplicated $P$. falciparum malaria [52]. Furthermore, in the athymic or scid/bg mouse model of malaria, a pro-oxidant vitamin E-deficient diet enriched with fish oil suppressed a lethal P. yoelii infection [53]. Although the actual molecular events leading to protection from malaria in mice fed this pro-oxidant diet were not elucidated, an enhanced pro-oxidant activity in these animals could have either directly killed the parasites or activated signalling pathways that could have contributed to the killing of $\mathrm{PE}$ via non-opsonic phagocytosis. In fact, ROS increase the expression of the scavenger receptor CD36 in monocytes/macrophages [54] and CD36 mediates nonopsonic phagocytosis of PE by macrophages $[16,55]$.

In addition to its specific anti-malarial activity, the immunomodulatory properties of curcumin affect various cell types of the immune system [Reviewed in [56]). When administered in vivo to mice, a significant increase in macrophage phagocytic activity was observed [57]. Furthermore, curcumin increased non-inflammatory phagocytosis of latex beads in murine macrophages in vitro[58]. From the same perspective, it was demonstrated that curcumin increased the surface expression of CD36 on human monocytes/macrophages and CD36dependent phagocytosis through a transient production of ROS which was downregulated by the anti-oxidant NAC [38]. Thus, these findings partly support the view that CD36 can be seen as a marker of the enhanced macrophage phagocytic activity observed in curcumintreated animals [57]. CD36 expression is regulated either by activation of the nuclear receptor PPAR $\gamma$ or by the redox-sensitive transcription factor nuclear related \{erythroid-derived 2$\}$ factor (Nrf2) [17,59]. Interestingly, these two transcription factors have been found to be activated in curcumin-treated monocytes/macrophages $[60,61]$, though experimental evidence suggested that curcumin is not a genuine PPAR $\gamma$ agonist [62]. To summarize, it is likely that curcumin enhances discrete factors implicated in the innate immune response to malaria infection (e.g CD36) via a cascade of events 
involving transient production of ROS resulting in PPAR $\gamma /$ Nrf2 activation and upregulation of monocytes/ macrophages CD36 surface expression and enhanced phagocytosis of PE (Figure 2).

\section{Curcumin downregulates proinflammatory cytokine} responses and expression of adhesion molecules on human endothelial cells in vitro

Cerebral malaria is the result of deleterious patholophysiological processes that take place in a Plasmodium-infected host [6]. In human malaria, a consistent histological finding in CM in both children and adults is the presence of infected and non-infected erythrocytes packed within cerebral microvessels [63]. This sequestration of PE and non-infected erythrocytes reduces the microvascular flow thereby causing disruption of blood brain barrier, cerebral oedema and tissue hypoxia [30, 63-64]. In addition, the release of neurotoxic and inflammatory mediators that may leak across the blood-brain barrier and cause more damage to the microvascular endothelium also contribute to this pathology (reviewed in [6]). The sequestration process is the result of increased expression of cytoadhesion molecules mainly ICAM1, VCAM1 and E-selectin on brain endothelial cells stimulated by the overproduction of inflammatory cytokines [65] or by the direct adhesion of P. falciparum to endothelial cells [66]. In fact, adhesion of $P$. falciparum to human brain endothelial cells in vitro creates an inflammatory environment via stimulation of NF- $\kappa \mathrm{B}$ which in turn upregulates expression of ICAM1 [66,67]. Most of the adjunctive therapies for the management of $\mathrm{CM}$ have been tested in mice and careful precautions should be taken when extrapolating findings from animal models to human CM [68]. However, some of the key features of human CM can also be replicated in the P. berghei model as discussed by Riley at al [69], making it reasonably suitable for preliminary evaluation of potential $\mathrm{CM}$ adjunctive therapies.

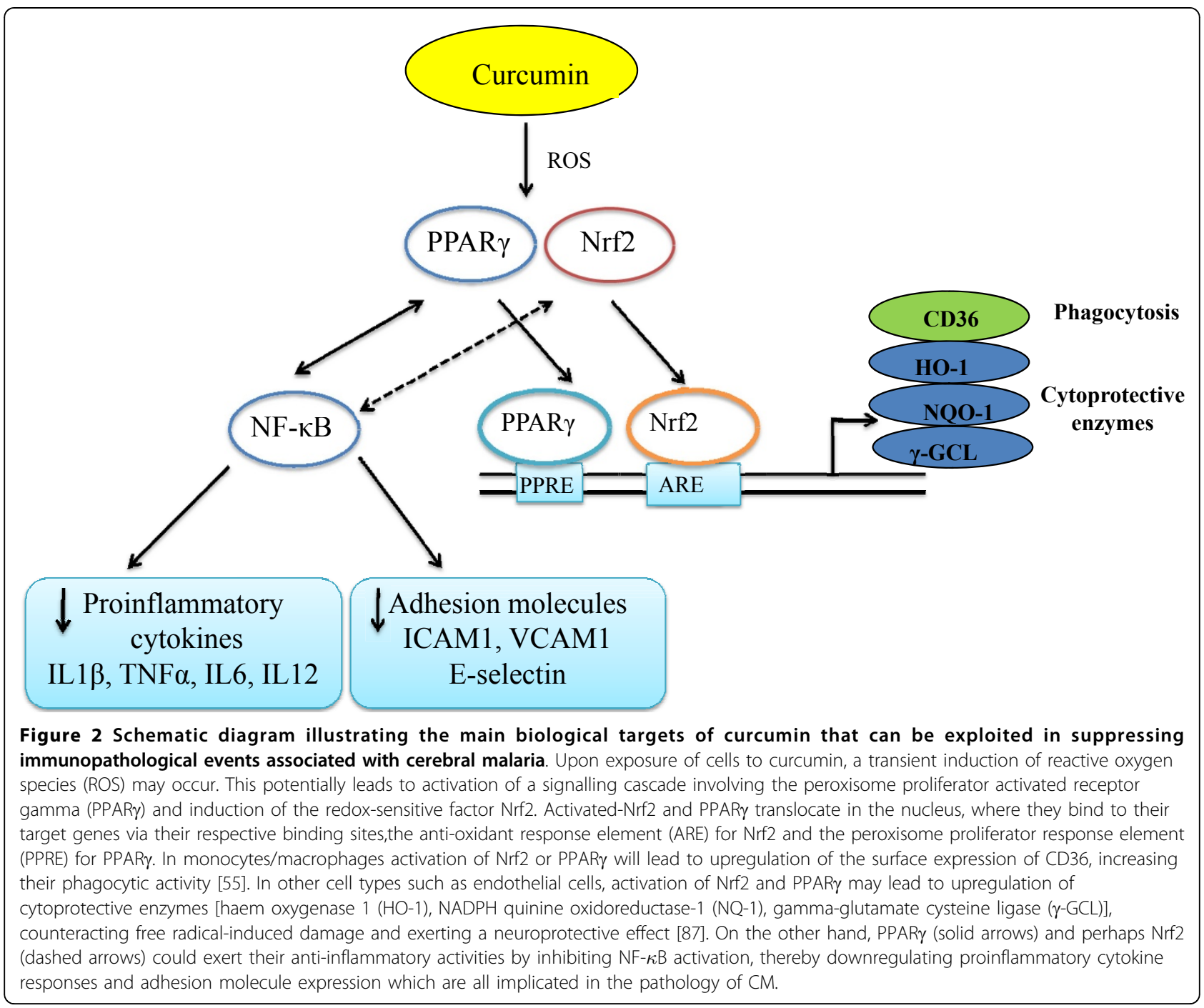


Curcumin exhibits profound anti-inflammatory activities due to inhibition of NF- $\kappa$ B activation [70]. This can explain the rationale for the use of curcumin in Ayurveda as a treatment for chronic inflammatory diseases [71]. This immunomodulatory property of curcumin may be useful in protecting the brain endothelium from the damages caused by the sequestration of PE. Curcumin administered in conjunction with the standard treatment for $\mathrm{CM}$, artesunate or quinine, might contribute to the reversal of parasite sequestration and inflamamtion, reducing the risk of neurological sequaelae. Interestingly, administration of curcumin $(50 \mathrm{mg} / \mathrm{kg}$, twice a day for 6 days post infection) to $\mathrm{C} 57 \mathrm{Bl} / 6$ mice infected with $P$. berghei-ANKA prevented CM and delayed death by 10 days [13]. In addition, it has been shown in vitro that curcumin reduces the production of proinflammatory cytokines TNF, IL12p40 and IL6 in PBMC primed with trophozoites/schizonts stages of $P$. falciparum and downregulated the expression of ICAM1, VCAM1 and E-selectin in TNF-activated human endothelial cells [38]. The down regulation of proinflammatory cytokines and adhesion molecules observed following PBMC exposure to curcumin in vitro, is perhaps the result of Nrf2 or PPAR $\gamma$ activation which exert anti-inflammatory actions by blocking NF- $\kappa$ B activation (Figure 2) [72]. In fact, in an animal model of traumatic brain injury it was observed that Nrf2 deficient mice have enhanced NF- $\kappa$ B activation, inflammatory cytokine production and increased ICAM1 expression in the brain compared to their wild type counterparts [73]. Furthermore, induction of haem oxygenase $1(\mathrm{HO}-1)$ which is a downstream target of the Nrf2 activation cascade (Figure 2) suppressed the pathology of ECM in mice [74] while activating Nrf2 pathway was demonstrated to be a potential therapeutic target in brain inflammation [75]. Curcumin inhibits the adhesion of thrombin-activated platelets to brain microvascular endothelial cells in vitro[76] which are thought to accumulate in the brain microvasculature in murine and paediatric CM patients [77]. Recent genome wide analysis studies of inbred mouse lines confirming the important role that PPAR $\gamma$ might have in malarial survival [19], support a therapeutic approach in which the targeting of this transcription factor (using curcumin for example) could be useful in the management of CM. In addition to PPAR $\gamma$, it might be worth investigating the effect of targeted deletion of Nrf2 in brain microvascular endothelial cells in vitro as well as in vivo in order to validate the Nrf2 activation pathway as an additional therapeutic target for CM.

In malaria endemic areas, both severe malaria and sepsis may often occur together [78]. In an animal model of sepsis, disruption of $\mathrm{Nrf2}$ was associated with a significant increase in proinflammatory cytokines and mortality in response to endotoxin-induced septic shock [79]. Management of severe malaria and sepsis could be supported with anti-inflammatory agents that may target Nrf2, such as curcumin, in combination with potent artemisinin derivatives. In fact, artemisinins also possess significant anti-inflammatory activity suppressing TNFa and IL-6 in a murine model of sepsis [80]. Moreover, the artemether-lumefantrine combination has been found to decrease mortality from sepsis in Ugandan children without malaria [81]. In a recent multicentre, open label, randomised trial comparing artesunate versus quinine (Aquamat Study) for the treatment of severe P. falciparum malaria in African children, intravenous artesunate has now been declared to be the most effective treatment for severe malaria [4]. This gives support to our view that if appropriately developed and approved for human use, curcumin or more potent derivatives could potentially be used with artesunate in the future. An open-labelled study to evaluate the safety of future curcumin formulations, combined with intravenous artesunate, examining as endpoints neurological sequelae or survival rate, should be carried out in future. Since treatment for CM is initiated after the onset of coma in most cases, it will be important to evaluate whether curcumin can reverse or shorten the comatose period and/or reduce the risk of neurological sequelae. We anticipate that due to its specific anti-malarial activity, it is unlikely that curcumin will exacerbate the evolution of $\mathrm{CM}$.

\section{Limitations for the use of curcumin in the clinic}

Although the information discussed above suggests a plausible and beneficial use of curcumin in the management of $\mathrm{CM}$, an important limitation hindering the clinical advancement of this promising molecule is its poor ADME properties. Curcumin shows low oral bioavailability, high tissue distribution, rapid metabolism and elimination $[57,82]$. The low bioavailability of curcumin is in part due to its hydrophobic nature and when administered orally, curcumin undergoes conjugation leading to the formation of curcumin glucuronide and sulfates in the intestinal wall and the liver [35]. Numerous strategies are currently being investigated to enhance curcumin's bioavailability. One of these approaches involved the use of a bioavailability enhancer such as piperine from black pepper. Piperine is an inhibitor of hepatic and intestinal glucuronidation which has enhanced the bioavailability of curcumin when administered in animal and human volunteers [83]. Other attempts to increase curcumin's bioavailability include liposomal curcumin [84], curcumin nanoparticles and curcumin-phospholipid complexes [85]. Thus, a successful enhancement of curcumin bioavailability that preserves its safety in humans is likely to bring this promising natural product 
to the forefront of therapeutic agents for the treatment of various conditions including malaria.

\section{Concluding remarks}

Curcumin has a long history of therapeutic use in the Ayurvedic and Chinese traditional medicine and multiple clinical trials are ongoing to evaluate its efficacy in the management of various human disorders including cancer, neurodegenerative diseases and diabetes [56] . Curcumin is considered a safe compound by the United States Food and Drug Administration and is commercially available as a dietary supplement (Figure 1). Curcumin is well-tolerated in humans and with respect to the management of $\mathrm{CM}$ might exert its therapeutic effects by inhibiting NF- $\kappa \mathrm{B}$ activation, followed by downregulation of proinflammatory cytokine production and expression of cytoadhesion molecules on endothelial cells. The fact that cytoadherence of the malaria parasite continues long after parasites have been killed by antimalarial drugs, supports the development of adjunctive therapies to reverse the pathophysiological consequences of cytoadherence [86]. With extensive research efforts ongoing to explore the clinical applications of curcumin in chronic inflammatory disorders, diabetes and cancer, the development of oral and parenteral curcumin formulations or curcumin analogues with improved bioavailability while retaining their immunomodulatory properties and possibly more potent anti-malarial activity deserves investigation. Drug discovery efforts focused on molecules with dual, immunomodulatory and antiparasitic action, may pave the way for their use as an adjunctive therapy for the management of uncomplicated and severe malaria.

\footnotetext{
Acknowledgements

Financial support: This work was supported by a grant from the European Commission Sixth Framework Programme FP6- IP-18834, AntiMal to DT from the University of Milan and LV from the London School of Hygiene and Tropical Medicine. PNM is recipient of a studentship from the AntiMal International $\mathrm{PhD}$ programme, an EMBL collaborative training programme. The European Commission had no role in study design, data collection, analysis or interpretation, the writing of the manuscript, or the decision to submit the work for publication.

This article has been published as part of Malaria Journal Volume 10 Supplement 1, 2011: Natural products for the control of malaria. The full contents of the supplement are available online at http://www.malariajournal.com/supplements/10/S1.
}

\section{Author details}

${ }^{1}$ Faculty of Infectious and Tropical Diseases, Department of Immunology and Infection, London School of Hygiene and Tropical Medicine, Keppel St, London WC1E 7HT, UK. ²Dipartimento di Sanità Pubblica -MicrobiologiaVirologia, Università di Milano, Via Carlo Pascal 36, 20133 Milano, Italy.

\section{Authors' contributions}

PNM drafted the manuscript. DT and LV participated in the writing and made corrections to the manuscript. All the authors read and approved the final version.

\section{Competing interests}

The authors declare that they have no competing interests related to this work.

Published: 15 March 2011

\section{References}

1. WHO: WHO world malaria report 2009. WHO publication Geneva: World Health Organization; 2009, 78.

2. Day N, Dondorp AM: The management of patients with severe malaria. Am J Trop Med Hyg 2007, 77(Suppl 6):29-35.

3. Dondorp AM, Nosten F, Yi P, Das D, Phyo AP, Tarning J, Lwin KM, Ariey F, Hanpithakpong W, Lee SJ, Ringwald P, Silamut K, Imwong M, Chotivanich K, Lim P, Herdman T, An SS, Yeung S, Singhasivanon P, Day NP, Lindegardh N, Socheat D, White NJ: Artemisinin resistance in Plasmodium falciparum malaria. N Engl J Med 2009, 361:455-467.

4. Dondorp AM, Fanello Cl, Hendriksen ICE, Gomes E, Seni A, Chhaganlal KD, Bojang K, Olaosebikan R, Anunobi N, Maitland K, Kivaya E, Agbenyega T, Nguah SB, Evans J, Gesase S, Kahabuka C, Mtove G, Nadjm B, Deen J, Mwanga-Amumpaire J, Nansumba M, Karema C, Umulisa N, Uwimana A, Mokuolu OA, Adedoyin OT, Johnson WB, Tshefu AK, Onyamboko MA, Sakulthaew T, Ngum WP, Silamut K, Stepniewska K, Woodrow CJ, Bethell D, Wills B, Oneko M, Peto TE, von Seidlein L, Day NP, White NJ, AQUAMAT group: Artesunate versus quinine in the treatment of severe falciparum malaria in African children (AQUAMAT): an open-label, randomised trial. Lancet 2010, 376:1647-1657.

5. Smith TG, Ayi K, Serghides L, McAllister CD, Kain KC: Innate immunity to malaria caused by Plasmodium falciparum. Clin Invest Med 2002, 25:262-272.

6. Hunt NH, Golenser J, Chan-Ling T, Parekh S, Rae C, Potter S, Medana IM, Miu J, Ball HJ: Immunopathogenesis of cerebral malaria. Int J Parasitol 2006, 36:569-582.

7. Schofield L, Grau GE: Immunological processes in malaria pathogenesis. Nat Rev Immunol 2005, 5:722-735.

8. Golenser J, McQuillan J, Hee L, Mitchell AJ, Hunt NH: Conventional and experimental treatment of cerebral malaria. Int J Parasitol 2006, 36:583-593.

9. Casals-Pascual C, Idro R, Picot S, Roberts DJ, Newton CRJC: Can erythropoietin be used to prevent brain damage in cerebral malaria? Trends Parasitol 2009, 25:30-36.

10. de Souza JB, Okomo U, Alexander ND, Aziz N, Owens BMJ, Kaur H, Jasseh M, Muangnoicharoen S, Sumariwalla PF, Warhurst DC, Ward SA, Conway DJ, Ulloa L, Tracey KJ, Foxwell BM, Kaye PM, Walther M: Oral activated charcoal prevents experimental cerebral malaria in mice and in a randomized controlled clinical trial in man did not interfere with the pharmacokinetics of parenteral artesunate. PLOS ONE 2010, 5:e9867.

11. Reis PA, Comim CM, Hermani F, Silva B, Barichello T, Portella AC, Gomes FCA, Sab IM, Frutuoso VS, Oliveira MF, Bozza PT, Bozza FA, DalPizzol F, Zimmerman GA, Quevedo J, Castro-Faria-Neto HC: Cognitive dysfunction is sustained after rescue therapy in experimental cerebral malaria, and is reduced by additive antioxidant therapy. PLOS Pathog 2010, 6:e1000963.

12. Serghides L, Patel SN, Ayi K, Lu Z, Gowda DC, Liles WC, Kain KC: Rosiglitazone modulates the innate immune response to Plasmodium falciparum infection and improves outcome in experimental cerebral malaria. J Infect Dis 2009, 199:1536-1545.

13. Waknine-Grinberg JH, McQuillan JA, Hunt N, Ginsburg H, Golenser J: Modulation of cerebral malaria by fasudil and other immune-modifying compounds. Exp Parasitol 2010, 125:141-146.

14. Charunwatthana P, Abul Faiz M, Ruangveerayut R, Maude RJ, Rahman MR, Roberts $\sqcup$ 2nd, Moore K, Bin Yunus E, Hoque MG, Hasan MU, Lee SJ, Pukrittayakamee S, Newton PN, White NJ, Day NP, Dondorp AM: Nacetylcysteine as adjunctive treatment in severe malaria: a randomized, double-blinded placebo-controlled clinical trial. Crit Care Med 2009, 37:516-522.

15. Picot S, Bienvenu AL, Konate S, Sissoko S, Barry A, Diarra E, Bamba K, Djimde A, Doumbo O: Safety of epoietin beta-quinine drug combination in children with cerebral malaria in Mali. Malar J 2009, 8:169.

16. McGilvray ID, Serghides L, Kapus A, Rotstein OD, Kain KC: Nonopsonic monocyte/macrophage phagocytosis of Plasmodium falciparum- 
parasitized erythrocytes: a role for CD36 in malarial clearance. Blood 2000, 96:3231-3240.

17. Serghides $L$, Kain KC: Peroxisome proliferator-activated receptor gamma\}retinoid $\mathrm{X}$ receptor agonists increase $\mathrm{CD} 36$-dependent phagocytosis of Plasmodium falciparum-parasitized erythrocytes and decrease malariainduced TNF-alpha secretion by monocytes/macrophages. J Immunol 2001, 166:6742-6748.

18. Boggild AK, Krudsood S, Patel SN, Serghides L, Tangpukdee N, Katz K, Wilairatana P, Liles WC, Looareesuwan S, Kain Kevin C: Use of peroxisome proliferator-activated receptor $\gamma$ agonists as adjunctive treatment for Plasmodium falciparum malaria: A randomized, double-blind, placebocontrolled trial. Clin Infect Dis 2009, 49:841-849.

19. Bopp SER, Ramachandran V, Henson K, Luzader A, Lindstrom M, Spooner M Steffy BM, Suzuki O, Janse C, Waters AP, Zhou Y, Wiltshire T, Winzeler EA: Genome wide analysis of inbred mouse lines identifies a locus containing ppar- $\gamma$ as contributing to enhanced malaria survival. PLOS ONE 2010, 5:e10903.

20. Kaiser K, Texier A, Ferrandiz J, Buguet A, Meiller A, Latour C, Peyron F, Cespuglio R, Picot S: Recombinant human erythropoietin prevents the death of mice during cerebral malaria. J Infect Dis 2006, 193:987-995.

21. Bienvenu AL, Ferrandiz J, Kaiser K, Latour C, Picot S: Artesunateerythropoietin combination for murine cerebral malaria treatment. Acta Trop 2008, 106:104-108.

22. Casals-Pascual C, Idro R, Gicheru N, Gwer S, Kitsao B, Gitau E, Mwakesi R, Roberts DJ, Newton CRJC: High levels of erythropoietin are associated with protection against neurological sequelae in African children with cerebral malaria. Proc Natl Acad Sci USA 2008, 105:2634-2639.

23. Kellum JA, Venkataraman R: Blood purification in sepsis: an idea whose time has come? Crit Care Med 2002, 30:1387-1388

24. Schulman G: A nexus of progression of chronic kidney disease: charcoal, tryptophan and profibrotic cytokines. Blood Purif 2006, 24:143-148.

25. Taoufiq Z, Gay F, Balvanyos J, Ciceron L, Tefit M, Lechat P, Mazier D: Rho kinase inhibition in severe malaria: Thwarting parasite-induced collateral damage to endothelia. J Infect Dis 2008, 197:1062-1073.

26. Zang-Edou ES, Bisvigou U, Taoufiq Z, Lékoulou F, Lékana-Douki JB, Traoré Y, Mazier D, Touré-Ndouo FS: Inhibition of Plasmodium falciparum field isolates-mediated endothelial cell apoptosis by Fasudil: Therapeutic implications for severe malaria. PLOS ONE 2010, 5:e13221.

27. Pino P, Vouldoukis I, Kolb Jean P, Mahmoudi N, Desportes-Livage I, Bricaire F, Danis M, Dugas B, Mazier D: Plasmodium falciparum-infected erythrocyte adhesion induces caspase activation and apoptosis in human endothelial cells. J Infect Dis 2003, 187:1283-1290.

28. Taoufiq Z, Pino P, Dugas N, Conti M, Tefit M, Mazier D, Vouldoukis !: Transient supplementation of superoxide dismutase protects endothelial cells against Plasmodium falciparum-induced oxidative stress. Mol Biochem Parasitol 2006, 150:166-173.

29. Mohanty S, P D, Pati SS, Mishra SK: Adjuvant therapy in cerebral malaria. Indian J Med Res 2006, 124:245-260.

30. Rowe JA, Claessens A, Corrigan RA, Arman Mn: Adhesion of Plasmodium falciparum-infected erythrocytes to human cells: molecular mechanisms and therapeutic implications. Expert Reviews in Molecular Medicine 2009, 11:e16.

31. Clark RL: Embryotoxicity of the artemisinin antimalarials and potential consequences for use in women in the first trimester. Reproductive Toxicology 2009, 28:285-296.

32. Mishra K, Dash AP, Swain BK, Dey N: Anti-malarial activities of Andrographis paniculata and Hedyotis corymbosa extracts and their combination with curcumin. Malar J 2009, 8:26.

33. Calabrese V, Bates TE, Mancuso C, Cornelius C, Ventimiglia B, Cambria MT, Renzo LD, Lorenzo AD, Dinkova-Kostova AT: Curcumin and the cellular stress response in free radical-related diseases. Mol Nutr Food Res 2008, 52:1062-1073.

34. Epstein J, Sanderson IR, MacDonald TT: Curcumin as a therapeutic agent: the evidence from in vitro, animal and human studies. Br J Nutr 2010 103:1545-1557.

35. Goel A, Kunnumakkara AB, Aggarwal BB: Curcumin as "Curecumin": From kitchen to clinic. Biochem Pharmacol 2008, 75:787-809.

36. Cui L, Miao J, Cui L: Cytotoxic effect of curcumin on malaria parasite Plasmodium falciparum: Inhibition of histone acetylation and generation of reactive oxygen species. Antimicrob Agents Chemother 2007, 51:488-494.
37. Reddy RC, Vatsala PG, Keshamouni VG, Padmanaban G, Rangarajan PN: Curcumin for malaria therapy. Biochem Biophys Res Comm 2005, 326:472-474.

38. Mimche PN: Modulation of Plasmodium falciparum phagocytosis, inflammatory cytokines production and cytoadhesion molecules expression by the natural product curcumin. PhD thesis EMBL/University of Milan-LSHTM, AntiMal programme; 2010.

39. Mishra S, Karmodiya K, Surolia N, Surolia A: Synthesis and exploration of novel curcumin analogues as anti-malarial agents. Bioorg Med Chem 2008, 16:2894-2902.

40. Haynes RK, Chan WC, Wong HN, Li KY, Wu WK, Fan KM, Sung HHY, Williams ID, Prosperi D, Melato S, Coghi P, Monti D: Facile oxidation of leucomethylene blue and dihydroflavins by artemisinins: Relationship with flavoenzyme function and antimalarial mechanism of action. ChemMedChem 2010, 5:1282-1299.

41. Wang J, Huang L, Li J, Fan Q, Long Y, Li Y, Zhou B: Artemisinin directly targets malarial mitochondria through its specific mitochondrial activation. PLOS ONE 2010, 5:e9582.

42. Ji HF, Shen L: Interactions of curcumin with the PfATP6 model and the implications for its antimalarial mechanism. Bioorg Med Chem Lett 2009, 19:2453-2455.

43. Singh N, Misra K: Computational screening of molecular targets in Plasmodium for novel non resistant anti-malarial drugs. Bioinformation 2009, 3:255-262

44. Eckstein-Ludwig U, Webb RJ, van Goethem IDA, East JM, Lee AG, Kimura M, O'Neill PM, Bray PG, Ward SA, Krishna S: Artemisinins target the SERCA of Plasmodium falciparum. Nature 2003, 424:957-961.

45. Krishna S, Uhlemann AC, Haynes RK: Artemisinins: mechanisms of action and potential for resistance. Drug Resist Updat 2004, 7:233-244.

46. Uhlemann AC, Cameron A, Eckstein-Ludwig U, Fischbarg J, Iserovich $P$, Zuniga FA, East M, Lee A, Brady L, Haynes RK, Krishna S: A single amino acid residue can determine the sensitivity of SERCAs to artemisinins. Nat Struct Mol Biol 2005, 12:628-629.

47. Nandakumar DN, Nagaraj VA, Vathsala PG, Rangarajan P, Padmanaban G: Curcumin-artemisinin combination therapy for malaria. Antimicrob Agents Chemother 2006, 50:1859-1860.

48. Martinelli A, Rodrigues LA, Cravo P: Plasmodium chabaudi: Efficacy of artemisinin + curcumin combination treatment on a clone selected for artemisinin resistance in mice. Exp Parasitol 2008, 119:304-307.

49. McMorran BJ, Marshall VM, de Graaf C, Drysdale KE, Shabbar M, Smyth GK, Corbin JE, Alexander WS, Foote SJ: Platelets kill intraerythrocytic malarial parasites and mediate survival to infection. Science 2009, 323:797-800.

50. Sandur SK, Ichikawa H, Pandey MK, Kunnumakkara AB, Sung B, Sethi G, Aggarwal BB: Role of pro-oxidants and antioxidants in the antiinflammatory and apoptotic effects of curcumin (diferuloylmethane). Free Radic Biol Med 2007, 43:568-580.

51. Strasser EM, Wessner B, Manhart N, Roth E: The relationship between the anti-inflammatory effects of curcumin and cellular glutathione content in myelomonocytic cells. Biochem Pharmacol 2005, 70:552-559.

52. Greve $B$, Lehman LAG, Lell B, Luckner D, Schmidt Ott R, Kremsner PAG: High oxygen radical production is associated with fast parasite clearance in children with Plasmodium falciparum malaria. $J$ Infect Dis 1999, 179:1584-1586

53. Taylor D, Levander O, Krishna V, Evans C, Morris V, Barta J: Vitamin Edeficient diets enriched with fish oil suppress lethal Plasmodium yoelii infections in athymic and scid/bg mice. Infect Immun 1997, 65:197-202.

54. Fuhrman B, Volkova N, Aviram M: Oxidative stress increases the expression of the CD36 scavenger receptor and the cellular uptake of oxidized low-density lipoprotein in macrophages from atherosclerotic mice: protective role of antioxidants and of paraoxonase. Atherosclerosis 2002, 161:307-316.

55. Serghides $L$, Smith TG, Patel SN, Kain KC: CD36 and malaria: friends or foes? Trends Parasitol 2003, 19:461-469.

56. Jagetia G, Aggarwal B: "Spicing up" of the immune system by curcumin J Clin Immunol 2007, 27:19-35.

57. Varalakshmi C, Ali AM, Pardhasaradhi BW, Srivastava RM, Singh S, Khar A Immunomodulatory effects of curcumin: In-vivo. Int Immunopharmacol 2008, 8:688-700.

58. Bisht K, Choi WH, Park SY, Chung MK, Koh WS: Curcumin enhances noninflammatory phagocytic activity of RAW264.7 cells. Biochem Biophys Res Comm 2009, 379:632-636. 
59. D'Archivio M, Scazzocchio B, Filesi C, Varì R, Maggiorella MT, Sernicola L, Santangelo C, Giovannini C, Masella R: Oxidised LDL up-regulate CD36 expression by the Nrf2 pathway in 3T3-L1 preadipocytes. FEBS Letters 2008, 582:2291-2298.

60. Rushworth SA, Ogborne RM, Charalambos CA, O'Connell MA: Role of protein kinase $C$ [delta] in curcumin-induced antioxidant response element-mediated gene expression in human monocytes. Biochem Biophys Res Comm 2006, 341:1007-1016.

61. Siddiqui AM, Cui $X$, Wu R, Dong W, Zhou M, Hu M, Simms HH, Wang P: The anti-inflammatory effect of curcumin in an experimental model of sepsis is mediated by up-regulation of peroxisome proliferator-activated receptor-gamma. Crit Care Med 2006, 34:1874-1882.

62. Narala VR, Smith MR, Adapala RK, Ranga R, Panati K, Moore BB, Leff T, Reddy VD, Kondapi AK, Reddy RC: Curcumin is not a ligand for peroxisome proliferator-activated receptor-gamma. Gene Ther Mol Biol 2009, 13:20-25.

63. Idro R, Jenkins NE, Newton CR: Pathogenesis, clinical features, and neurological outcome of cerebral malaria. Lancet Neurol 2005, 4:827-840.

64. Dondorp AM: Clinical significance of sequestration in adults with severe malaria. Transfus Clin Biol 2008, 15:56-57.

65. Hunt NH, Grau GE: Cytokines: accelerators and brakes in the pathogenesis of cerebral malaria. Trends Immunol 2003, 24:491-499.

66. Tripathi AK, Sullivan DJ, Stins MF: Plasmodium falciparum-infected erythrocytes increase intercellular adhesion molecule 1 expression on brain endothelium through NF-kappaB. Infect Immun 2006, 74(6):3262-3270.

67. Tripathi AK, Sha W, Shulaev V, Stins MF, Sullivan DJ Jr: Plasmodium falciparum-infected erythrocytes induce NF-kappaB regulated inflammatory pathways in human cerebral endothelium. Blood 2009, 114:4243-4252.

68. White NJ, Turner GD, Medana IM, Dondorp AM, Day NP: The murine cerebral malaria phenomenon. Trends Parasitol 2009, 26:11-15.

69. Riley EM, Couper KN, Helmby H, Hafalla JCR, Souza JBd, Langhorne J, Jarra W, Zavala F: Neuropathogenesis of human and murine malaria. Trends Parasitol 2010, 26:277-278.

70. Chan MMY: Inhibition of tumor necrosis factor by curcumin, a phytochemical. Biochemical Pharmacology 1995, 49:1551-1556.

71. Aggarwal BB, Sung B: Pharmacological basis for the role of curcumin in chronic diseases: An age-old spice with modern targets. Trends Pharmacol Sci 2009, 30:85-94.

72. Straus DS, Glass CK: Anti-inflammatory actions of PPAR ligands: new insights on cellular and molecular mechanisms. Trends Immunol 2007, 28:551-558.

73. Jin W, Wang $H$, Yan W, Xu L, Wang $X$, Zhao $X$, Yang $X$, Chen G, Ji Y: Disruption of Nrf2 enhances upregulation of nuclear factor-kappaB activity, proinflammatory cytokines, and intercellular adhesion molecule1 in the brain after traumatic brain injury. Mediators Inflamm 2008, 2008:725174.

74. Pamplona A, Ferreira A, Balla J, Jeney V, Balla G, Epiphanio S, Chora A, Rodrigues CD, Gregoire IP, Cunha-Rodrigues M, Portugal S, Soares MP, Mota MM: Heme oxygenase- 1 and carbon monoxide suppress the pathogenesis of experimental cerebral malaria. Nat Med 2007, 13:703-710.

75. Innamorato NG, Rojo Al, Garcia-Yague AJ, Yamamoto M, de Ceballos ML, Cuadrado A: The transcription factor Nrf2 is a therapeutic target against brain inflammation. J Immunol 2008, 181:680-689.

76. Zhang L, Gu ZL, Qin ZH, Liang ZQ: Effect of curcumin on the adhesion of platelets to brain microvascular endothelial cells in vitro. Acta Pharmacol $\operatorname{Sin} 2008,29: 800-807$.

77. Faille D, El-Assaad F, Alessi MC, Fusai T, Combes V, Grau GE: Plateletendothelial cell interactions in cerebral malaria: the end of a cordial understanding. Thromb Haemost 2009, 102:1093-1102.

78. Berkley J, Mwarumba S, Bramham K, Lowe B, Marsh K: Bacteraemia complicating severe malaria in children. Trans R Soc Trop Med Hyg 1999, 93:283-286.

79. Thimmulappa RK: Nrf2 is a critical regulator of the innate immune response and survival during experimental sepsis. J Clin Invest 2006, 116:984-995.

80. Wang J, Zhou H, Zheng J, Cheng J, Liu W, Ding G, Wang L, Luo P, Lu Y, Cao H, Yu S, Li B, Zhang L: The antimalarial artemisinin synergizes with antibiotics to protect against lethal live Escherichia coli challenge by decreasing proinflammatory cytokine release. Antimicrob Agents Chemother 2006, 50:2420-2427.

81. Moore CC, Jacob ST, Pinkerton R, Banura P, Meya DB, Reynolds SJ, KenyaMugisha N, Mayanja-Kizza H, Scheld WM, Promoting Resource-Limited Interventions for Sepsis Management in Uganda (PRISM-U) Study Group: Treatment of severe sepsis with artemether-lumefantrine is associated with decreased mortality in ugandan patients without malaria. Am J Trop Med Hyg 2009, 80:723-728.

82. Shehzad A, Khan S, Shehzad O, Lee YS: Curcumin therapeutic promises and bioavailability in colorectal cancer. Drugs Today (Barc) 2010, 46:523-532.

83. Shoba G, Joy D, Joseph T, Majeed M, Rajendran R, Srinivas PS: Influence of piperine on the pharmacokinetics of curcumin in animals and human volunteers. Planta Med 1998, 64:353-356.

84. Takahashi M, Uechi S, Takara K, Asikin Y, Wada K: Evaluation of an oral carrier system in rats: bioavailability and antioxidant properties of liposome-encapsulated curcumin. J Agric Food Chem 2009, 57:9141-9146.

85. Yadav VR, Suresh S, Devi K, Yadav S: Novel formulation of solid lipid microparticles of curcumin for anti-angiogenic and anti-inflammatory activity for optimization of therapy of inflammatory bowel disease. J Pharm Pharmacol 2009, 61:311-321.

86. Hughes KR, Biagini GA, Craig AG: Continued cytoadherence of Plasmodium falciparum infected red blood cells after antimalarial treatment. Mol Biochem Parasitol 2010, 169:71-78.

87. Lee JS, Surh YJ: Nrf2 as a novel molecular target for chemoprevention. Cancer Letters 2005, 224:171-184.

\section{doi:10.1186/1475-2875-10-S1-S10}

Cite this article as: Mimche et al:: The plant-based immunomodulator curcumin as a potential candidate for the development of an adjunctive therapy for cerebral malaria. Malaria Journal 2011 10(Suppl 1): S10.

\section{Submit your next manuscript to BioMed Central and take full advantage of:}

- Convenient online submission

- Thorough peer review

- No space constraints or color figure charges

- Immediate publication on acceptance

- Inclusion in PubMed, CAS, Scopus and Google Scholar

- Research which is freely available for redistribution

Submit your manuscript at www.biomedcentral.com/submit
Ciomed Central 